\title{
Uji Kualitas Kain Loreng Militer Pixel Design Berbasis SNI-ISO
}

\author{
Budiman Adi Setyawan $^{1 *}$, Ahmad Zayadi \\ ${ }^{1}$ Program Studi Teknik Perkapalan Fakultas Teknik Universitas Pembangunan Nasional Veteran \\ Jakarta \\ ${ }^{2}$ Program Studi Teknik Mesin Fakultas dan Teknik Sains Universitas Nasional Jakarta \\ *Korespondensi penulis: budimanadisetyawan9@gmail.com
}

\begin{abstract}
Abstrak. Seragam loreng pixell design yang dipakai oleh salah satu pasukan asing pada saat perang di Timur Tengah sangat menarik sehingga digemari oleh kalangan sipil di seluruh dunia dan dicari cari untuk dijadikan barang koleksi. Kain loreng tersebut diproduksi di Indonesia dan dievaluasi kualitasnya berdasarkan ISO/SNI, dengan hasil berat $\mathrm{m}^{2}$ (SNI-ISO 3801:2010) 213.1 gram. Konstruksi (tetal lusi dan pakan/cm) (SNI-ISO 7211-2:2010) 42.0 dan 20.0. Nomor benang lusi dan pakan $\mathrm{Ne}_{1}$ (SNI-ISO 7211-5:2010) 20.0 dan 15.0. Anyaman (SNI-ISO 7211-1:2010) keper 2/1/1. Kekuatan tarik N (kg) dan mulur (\%) arah lusi dan pakan (SNI 0276: 2009) $630.0(63,89)$ dan 11,0 \% lusi serta 345.0 (34.87) dan $12.0 \%$ (pakan). Kekuatan sobek N (g) arah lusi dan pakan (SNI-ISO 13937-1:2010) 37.9 (3,863) dan 33.8 $(3,442)$. Komposisi C/P (SNI-ISO 1833-11:2011) C/P 70.0\% /30.0\%. Ketahanan cuci (SNI ISO 105-C06:2010) nilainya 4-5. Ketahanan gosok (SNI-ISO 105X12.2012) 4 (kering) dan 3 (basah). Ketahanan sinar matahari (SNI-ISO 105B01:2010) menunjukkan angka 4-5 pada blue wool scale. Uji Identifikasi zat warna (SNI 08-0519:1989) dan (SNI 08-0621:1989) adanya zat warna dispersi dan zat warna bejana. Dalam penelitian ini, kain loreng militer mempunyai sifat fisik seerti kekuatan mekanis yang baik karena memenuhi standar ISO-SNI.
\end{abstract}

Kata kunci: benang lusi, blue wool scale, pakam, kekuatan tarik, SNI-ISO

\section{PENDAHULUAN}

Seragam loreng merupakan salah satu alat pendukung militer setiap negara di dunia. Oleh sebab itu masing-masing negara berusaha saling mengungguli satu sama lainnya. Disain dan motif seragam loreng militer dari negara maju selalu menarik perhatian masyarakat di seluruh dunia termasuk juga Indonesia. Penggemarnya bukan hanya dari kalangan militer saja tetapi juga dari masyarakat sipil yang banyak yang berburu seragam ini untuk dijadikan barang koleksi. Secara kebetulan banyak pakaian seragam tersebut dibuat di Indonesia. Tentara dari negara-negara barat (Eropa dan Amerika) pada umumnya mempunyai postur tinggi besar, berkulit putih, gagah dan tampan atau dari Afrika yang berkulit hitam, tinggi besar dan terkesan seram membuat pemakainya tampak berwibawa dan gagah. Setiap negara di dunia terus mengembangkan seragam lorengnya dengan ciri khas masing masing misalnya fauna atau flora yang menjadi ikon negara tersebut, seperti Korea Selatan, Indonesia, Jerman, Swedia, Amerika Serikat dan Israel merupakan negaranegara yang unggul dalam riset dan pengembangan seragam militernya. Pengembangan kualitas kain loreng bukan hanya sebatas pada kekuatan mekanisnya saja melainkan telah meluas kepada anti infra red, anti nyamuk, multi kamulfase dan sebagainya [1].

Adanya perbedaan kualitas loreng pada setiap negara akan berpengaruh pada penampilan pasukan militernya di dunia. Termasuk penampilan pasukan Tentara Nasional Indonesia (TNI) yang sering bergabung kedalam Pasukan Perdamaian PBB dimana nama bangsa dipertaruhkan. Postur anggota TNI yang relatif lebih kecil dibandingkan dengan pasukan barat akan menjadi pemandangan yang kontras karena berbeda kualitas lorengnya. Oleh sebab itu perlu diteliti kelebihan seragam militer dari negara-negara asing terutama Eropa, Amerika, Korea Selatan dan Jepang agar Indonesia dapat membuat seragam 
militer yang sama kualitasnya. Tidak banyak industri tekstil di dunia yang dapat membuat pakaian militer yang memenuhi standar. Beberapa persyaratan standar antara lain struktur kainnya harus kuat akan tetapi fleksibel, tidak kaku dan tidak mudah sobek, warnanya tidak boleh luntur, nyaman dipakai, pada saat cuaca panas memberikan rasa sejuk dan pada saat cuaca dingin menjadi hangat dan lain lain. Pakaian loreng untuk perang kota tidak sama dengan perang hutan atau gurun. Pemilihan loreng yang tepat pada waktu perang sangatlah penting karena jika salah pilih loreng akan fatal [2]. Alih-alih ingin melakukan penyamaran malah ketahuan dengan jelas oleh musuh. Oleh sebab itu setiap negara harus mempunyai koleksi seragam militer yang cukup banyak sehingga bisa menyesuaikan dengan medan operasinya [3].

Loreng pixel design mempunyai disain, konstruksi, komposisi dan kekuatan mekanis yang baik berdasarkan metoda uji SNI-ISO. Adanya perbedaan kualitas loreng militer dari suatu negara terhadap negara lainnya adalah suatu hal yang biasa tatkala pasukannya bertugas di negaranya masing-masing. Tetapi akan menjadi masalah apabila pasukan suatu negara bergabung dalam latihan ataupun operasi bersama pasukan dari negara lain misalnya dalam latihan bersama bilateral, regional ataupun internasional. Untuk itu perlu diungkap jika ada perbedaan kualitas terhadap seragam loreng melalui penelitian dan pengujian yang mengacu kepada suatu standar yang resmi. Selain itu untuk mengetahui sejauh mana kualitas loreng TNI yang telah dibuat mampu mengimbangi loreng negara lain dalam penampilannya di forum dunia [4].

Pixel adalah komponen paling kecil dari gambar digital atau representasi sebuah titik terkecil dalam sebuah gambar grafis yang dihitung per inci. Pixel sendiri berasal dari akronim bahasa Inggris Picture Element yang disingkat menjadi Pixel. Namun penjelasan piksel bukan hanya itu saja seperti piksel yang dicetak pada suatu kertas dengan mesin cetak, piksel yang dibawa oleh sinyal elektrik, piksel dalam layar, piksel dalam kamera digital dan sebagainya [5]. Dalam hal ini pixel desain yang dimaksudkan adalah motif atau corak suatu bahan tekstil untuk kegunaan khusus militer yang bersumber dari komponen paling kecil dari suatu gambar digital yang kemudian diperbesar. Sebuah gagasan yang mencoba mengambil gambar digital dalam skala piksel menjadi sebuah motif loreng baru yang dapat digunakan untuk tugas penyamaran sesuai dengan medan operasi yang sesuai. Loreng jenis ini tidak mengandung corak dan warna yang ekstrim sehingga sangat cocok untuk daerah operasi hutan semak sampai gurun pasir. Bukan untuk hutan lebat atau hutan bersalju.

Serat kapas adalah serat alam yang memiliki sifat yang memenuhi syarat sebagai salah satu unsur pakaian seperti kekuatan tarik yang tinggi, mempunyai daya serap air yang tinggi, tahan terhadap zat kimia tertentu, dapat mulur sampai pada panjang tertentu sebelum putus dan sebagainya. Serat kapas dengan panjang lebih dari 2 inci digunakan untuk pakaian yang halus/ringan misalnya untuk bahan kemeja formil pria. Serat kapas yang panjangnya 1-2 inci dipakai untuk pakaian dengan kualitas sedang misalnya untuk celana denim. Sedangkan serat dengan panjang dibawah 1.0 inci dipakai untuk pakaian dengan kualitas berat seperti celana jeans dan tenda. Serat kapas yang mutunya baik diimpor dari Mesir, Cina dan Amerika. Indonesia juga memiliki pertanian kapas seperti di Sulawesi Selatan dan Nusa Tenggara Timur namun produksinya belum dapat mencukupi kebutuhan industri dalam negeri dan kualitasnya belum dapat menyamai kapas impor [6].

Serat poliester adalah serat buatan yang berasal dari sintesis asam tereftalat dengan etilen glikol. Serat ini bersifat hidrofob, memiliki kekuatan tarik dan mulur yang tinggi, tahan terhadap jamur dan beberapa zat kimia dan lain lain. Harganya lebih murah dari pada kapas sehingga jika dicampurkan dengan kapas akan dapat menekan biaya produksi. Pemakaiannya untuk daerah tropis bisa dicampur dengan kapas sehingga akan saling menutupi kekurangan masing-masing. Kain campuran untuk fashion biasanya memiliki komposisi $65 / 35 \%$. Tujuannya adalah agar kain yang dihasilkan dapat bersifat wash and wear yang disebabkan dari sifat poliester yang lebih menonjol tetapi masih dapat menyerap air (keringat). Berbeda dengan kebutuhan militer, pakaian militer dituntut persyaratan yang lebih baik. Bukan hanya kekuatannya saja yang tinggi, daya serap 
airnya pun harus tinggi tetapi tetap kuat dan bersifat wash and wear. Maka kain untuk pakaian khusus militer dibuat dari bahan campuran poliester dan kapas dengan komposisi (P/C) 35/65\%. Kain yang terbuat dari campuran P/C 35/65\% mempunyai kekuatan yang baik dan daya serap air yang tinggi sehingga pemakainya tetap merasa sejuk ketika cuaca panas dan merasa hangat pada saat cuaca dingin.

Pewarnaan kain loreng yang dibuat dari campuran polyester/kapas 35/65\% harus memakai dua macam zat warna. Hal itu karena kain yang akan diproses terdiri dari dua macam serat yang berbeda sifatnya. Pewarna yang dipakai untuk itu biasanya campuran pewarna disperse dan bejana. Selain itu teknologi pewarnaannyapun dikerjakan dalam dua proses yang berbeda [7].

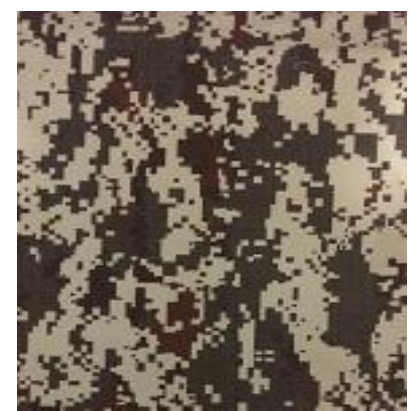

GAMBAR 1. Kain loreng Pixel Design.

Metoda yang akan digunakan adalah eksperimental proses manufaktur dan evaluasi berdasarkan Standar Nasional Indonesia. Nilai keterbaruan dari penelitian ini adalah digunakannya Standar Nasional Indonesia (SNI-ISO) sebagai alat ukur kualitas produk dalam negeri yang digunakan untuk mengukur kualitas produk standar ekspor yang akan dipakai di negara lain.

\section{METODOLOGI PENELITIAN.}

Produk yang dibuat yaitu Kain Loreng dengan motif pixel design dengan ketentuan umum yang sama dalam hal disain, konstruksi dan komposisi dengan metoda eksperimental. Ketentuan ketentuan tersebut dapat dilihat pada tabel 1.

Sampel telah terkondisi secara seragam dalam bentuk campuran standar T/C dan telah memenuhi syarat untuk diproduksi secara massal. Untuk sampel kapas diimpor dari Cina dengan kualitas baik, Sedangkan poliesternya buatan dalam negeri. Bahan untuk kain loreng "Pixel Design" tersedia masing-masing 200kilogram untuk diproses spinning, weaving, dyeing, printing dan finishing. Selanjutnya pada bagian akhir dilakukan evaluasi terhadap kualitas kedua produk loreng tersebut. Pengumpulan Data dilakukan terhadap sampel uji masing-masing sebanyak 10 kali untuk setiap variable rancangan kemudian dirata-ratakan. Metoda yang digunakan adalah metoda pengujian berdasarkan Standar Nasional Indonesia (SNI). Pengujian-pengujian tersebut sesuai dengan referensi [9].

Cara pengujian berat kain berdasarkan SNI/ISO 3801:2010 adalah dengan menimbang kain uji seluas $1010 \mathrm{~cm}^{2}$ pada timbangan analitis sebanyak 10 kali kemudian dirataratakan. Untuk menyesuaikan dengan ketentuan satuannya yaitu $\mathrm{g} / \mathrm{m}^{2}$ berat kain uji tersebut dikalikan 100 sehingga didapat berat $/ \mathrm{m}^{2}$.

Konstruksi kain meliputi SNI-ISO 7211-2:2010 tetal lusi dan pakan, SNI-ISO 72115:2010 tentag nomor benang lusi dan pakan dan SNI-ISO 7211-1:2010 tentang anyaman. Lusi adalah benang yang sejajar panjang kain sedangkan pakan adalah benang yang sejajar lebar kain. Cara uji tetal lusi dan pakan adalah dengan mengukur berapa banyak benang lusi dan pakan seluas $1.0 \mathrm{~cm}^{2}$ atau 1.0 inci $^{2}$ memakai kaca pembesar. Pengerjaan ini dilakukan 10 kali lalu dirata-ratakan. Hasilnya adalah tetal lusi dan pakan per $\mathrm{cm}^{2}$ atau inci $^{2}$. Nomor benang lusi dan pakan mempunyai dua satuan yaitu $\mathrm{Ne}_{1}$ (British) dan Tex (Germany). Cara uji $\mathrm{Ne}_{1}$ adalah dengan mengukur sehelai benang sepanjang 1yard lalu 
ditimbang beratnya dalam grain. Sedangkan cara uji Tex adalah dengan menimbang benang 1 gram kemudian diukur panjangnya dalam meter. Cara pengujian anyaman kain adalah dengan mengamati bentuk persilangan antara benang lusi dan pakan tiap $1.0 \mathrm{~cm}^{2}$ atau 1.0 inci $^{2}$ dengan menggunakan kaca pembesar. Adapun bentuk anyaman antara lain plat (ketupat), keper (bilik).

TABEL 1. Rancangan disain, konstruksi dan komposisi kain loreng berdasarkan SNI/ISO [8].

\begin{tabular}{|c|c|c|}
\hline \multirow{2}{*}{$\begin{array}{l}\text { VARIABEL RANCANGAN } \\
\text { Berat Kain } / \mathrm{m}^{2}\end{array}$} & \multicolumn{2}{|c|}{ STANDAR UMUM (SNI/ISO) } \\
\hline & SNI ISO 3801:2010 & $200-300$ \\
\hline \multicolumn{3}{|l|}{ Konstruksi Kain } \\
\hline Tetal lusi (vertikal) helai/cm (in) & SNI/ISO 7211-2:2010 & $35-45$ \\
\hline Tetal Pakan (horizontal) helai/cm (in) & SNI/ISO 7211-2:2010 & $15-20$ \\
\hline Besar & & - \\
\hline Kecil & & - \\
\hline Nomor benang lusi (vertikal) $\mathrm{Ne}_{1}(\mathrm{Tex})$ & SNI/ISO 7211-5:2010 & $15-20$ \\
\hline Nomor benang pakan (horizontal) $\mathrm{Ne}_{1}(\mathrm{Tex})$ & SNI/ISO 7211-5:2010 & $15-20$ \\
\hline Anyaman & SNI/ISO 7211-1:2010 & Keper/Rib \\
\hline \multicolumn{3}{|l|}{ Kekuatan Tarik dan Mulur } \\
\hline Kekuatan Tarik arah lusi (vertikal) N (kg) & SNI/ISO $0276: 2009$ & $500-600$ \\
\hline Mulur (\%) & SNI/ISO $0276: 2009$ & $10-15$ \\
\hline Kekuatan Tarik arah pakan (Horizontal) N (kg) & SNI/ISO $0276: 2009$ & $300-350$ \\
\hline Mulur (\%) & SNI/ISO 0276 : 2009 & $10-15$ \\
\hline \multicolumn{3}{|l|}{ Kekuatan Sobek Kain } \\
\hline Arah lusi (vertikal) N (g) & SNI/ISO 13937-1:2013 & $35-55$ \\
\hline Arah pakan (horizontal) N (g) & SNI/ISO 13937-1:2013 & $25-35$ \\
\hline \multicolumn{3}{|l|}{ Komposisi $(\%)$} \\
\hline Kapas & SNI/ISO 1833-11:2011 & $65-70$ \\
\hline Poliester & SNI/ISO 1833-11:2011 & $35-30$ \\
\hline \multicolumn{3}{|l|}{ Ketahanan Luntur Warna } \\
\hline a. Pencucian (GS/SS) & SNI/ISO 105-C06:2010 & $(4-5)$ \\
\hline b. Gosokan (kering/ basah) & SNI/ISO 105-X12:2012 & $(4 / 3)$ \\
\hline \multicolumn{3}{|l|}{ c. Keringat } \\
\hline Asam(GS/SS) & SNI/ISO 105-E04:2015 & $(4-5)$ \\
\hline Basa & SNI/ISO 105-E04:2015 & $(4-5)$ \\
\hline d. Sinar Matahari & SNI/ISO 105-B01:2010 & $4-5$ \\
\hline \multicolumn{3}{|l|}{ Identifikasi zat warna pada serat } \\
\hline Kapas & SNI 08-0621:1989 & Vat/Bejana \\
\hline Poliester & SNI 08-0519:1989 & Disperse \\
\hline
\end{tabular}

Pada kekuatan tarik dan mulur kain SNI-ISO 0276:2009 (arah lusi dan pakan), pengujian dilakukan dengan uji kekuatan tarik dan mulur kain pada dasarnya sama dengan logam atau non logam yaitu dengan cara membuat sampel uji $20 \times 2.5 \mathrm{~cm}^{2}$ yang dijepitkan pada klem mesin uji tarik kemudian ditarik sampai putus dipertengahannya. Pengujian ini diulang 10 kali lalu dirata-ratakan.

Untuk pengujian kekuatan sobek kain SNI-ISO 13937-1:2013 (arah lusi dan pakan), pengujian dilakukan dengan mesin uji Elmendorf yaitu dengan membuat sampel ukuran $10 \times 10 \mathrm{~cm}^{2}$ yang dijepitkan pada klem kemudian pisau berayun menyobek sampel. Maka kekuatan sobek adalah besarnya gaya $(\mathrm{N})$ yang dibutuhkan untuk menyobek sampel.

Untuk komposisi SNI-ISO 1833-11:2011 (kapas dan poliester), cara uji komposisi adalah dengan melarutkan salah satu material dengan reagen yang dapat melarutkannya. Sisa material yang tidak larut berarti komponen lain yang dapat diketahui jenisnya. Material sisa dikeringkan sampai kadar airnya 0\% lalu ditimbang sampai berat tetap.

Untuk ketahanan pewarna SNI-ISO 105-C06:2010 tentang pencucian, SNI ISO105X12:2012 tentang gosokan, SNI-ISO105-E04:2015 tentang keringat, SNI-ISO 105B01:2010 tentang sinar terang hari), pengujian dilakukan terhadap ketahanan luntur terhadap pencucian adalah dengan membuat sampel $10 \times 10 \mathrm{~cm}^{2}$ yang dijepit dengan kain standar lalu diproses di dalam mesin uji launderometer selama 15 menit pada temperatur $40^{\circ} \mathrm{C}$. Penodaan pada kain standar diukur dengan staining scale dan perubahan warna pada sampel uji diukur dengan gray scale. Nilai yang didapat merupakan nilai ketahanan luntur kain tersebut. Cara uji ketahanan luntur warna terhadap gosokan adalah dengan 
mengamati sampel uji berukuran $20 \times 2.0 \mathrm{~cm}^{2}$ yang diletakkan pada alat crock meter yang diberi kain standar dan digosok 20 kali maju mundur, lima kali dalam keadaan kering dan lima kali dalam keadaan basah. Penodaan warna pada kain putih standar diukur dengan staining scale. Perubahan warna sampel uji diukur dengan gray scale. Hasilnya merupakan nilai ketahanan gosok dari sampel uji. Cara uji ketahanan keringat adalah dengan merendam sampel uji yang dijepit kain standar berukuran $10 \times 10 \mathrm{~cm}^{2}$ di dalam larutan keringat buatan yang bersifat asam dan basa selama 10 menit. Sampel uji dan standar dikeringkan lalu diamati perubahan warna dan penodaannya pada staining scale dan gray scale. Nilai yang didapat adalah nilai ketahanan luntur warna terhadap keringat. Cara uji ketahanan terhadap sinar terang hari adalah dengan cara menjemur sampel uji yang disejajarkan dengan standar kain wol biru berukuran $2 \times 10 \mathrm{~cm}^{2}$ pada sinar matahari antara pukul 09:00 sampai dengan 15:00. Perubahan warna pada sampel uji dinilai dengan blue wool scale. Hasilnya merupakan nilai ketahanan luntur terhadap sinar terang hari.

Pada golongan zat pewarna menggunakan SNI 08-0519:1989 (zat pewarna dispersi) dan SNI 08-0621:1989 tentang zat pewarna bejana. Cara pengujian golongan zat pewarna pada material campuran tekstil menggunakan metoda pelarutan terhadap salah satu zat pewarna dengan reagensia tertentu (polar/nonpolar. Salah satu zat warna akan larut dan sebaliknya. Zat warna yang dipakai akan diketahui karena sifatnya yang larut pada salah satu reagensia tersebut [9].

Semua data yang diperoleh dari hasil pengujian dikelompokkan berdasarkan variabel rancangan seperti pada tabel 1. Namun untuk lebih akuratnya proses proses pengujian sampel, evaluasi terhadap data-data yang diperoleh sepenuhnya diserahkan kepada Unit Industri Kerajinan dan Tekstil Dinas Perindustrian dan Energi Propinsi DKI Jakarta untuk diuji secara legal dan bersertifikat. Dengan demikian keakuratan didalam proses pengujian, evaluasi dan analisis data maupun interpretasinya dapat dipertanggung jawabkan secara institusional [10].

\section{HASIL DAN PEMBAHASAN}

Berat Kain loreng pixel design sebesar $\left(213.0 \mathrm{~g} / \mathrm{m}^{2}\right)$. Contoh uji masih termasuk kedalam jenis berat kain sedang. Seragam militer di seluruh dunia pada umumnya mempunyai berat yang masuk kedalam katagori sedang. Mengingat bahwa beban yang dibawa oleh seorang tentara pada saat operasi cukup banyak seperti senjata, peluru, alat komunikasi, alat minum dan makan dan lain-lain. Ada 2 (dua) katagori berat yang lain yang berlaku umum didalam pembuatan bahan tekstil yaitu Berat kain katagori ringan $\left(<200 \mathrm{~g} / \mathrm{m}^{2}\right)$ contohnya adalah kemeja pria yang high quality atau busana wanita dari sutera dan Berat kain katagori berat $\left(>300 \mathrm{~g} / \mathrm{m}^{2}\right)$ contohnya denim atau jeans. Khusus untuk seragam militer tidak dipilih keduanya karena jika terlalu ringan akan berpengaruh pada penampilan dan jika terlalu berat akan menambah berat beban sehingga akan mempengaruhi kecepatan bergerak di dalam operasi militer.

Tetal lusi loreng pixel design 42.0/105.0. Tetal pakannya 20.0/50.0, nomor benang lusi $\mathrm{Ne}_{1}$ (Tex) 20.0 (29.4), Nomor benang pakan $\mathrm{Ne}_{1}$ (Tex) 15.0 (40.0) dan Bentuk anyamannya adalah keper 2/1/1 (bilik) sama dengan SNI-ISO. Konstruksi kain seperti ini merupakan ciri khas bahan tekstil untuk kegunaan khusus (militer). Dengan jumlah benang lusi ke arah vertikal 42 helai/cm atau 105 helai/inci) menunjukkan bahwa kain ini tersusun dari benang lusi kearah vertikal yang padat. Tujuannya adalah untuk membentuk kekuatan yang tinggi ke arah vertikal kain, mengingat bahwa beban ke arah ini lebih besar bila dibandingkan dengan ke arah horizontal. Sedangkan Tetal benang pakan (ke arah horizontal) hanya 20.0 helai/cm atau 50 helai/inci saja sudah cukup kuat untuk menahan beban ke arah horizontal. Hal itu didukung oleh ukuran benang atau nomor benang $\mathrm{Ne}_{1} 20$ dan $\mathrm{Ne}_{1} 15$ yang relativ hampir sama untuk arah vertikal untuk lusi maupun horizontal untuk pakan serta anyaman keper 2/1/1 berbentuk bilik yang 
membentuk sebuah konstruksi yang kokoh tetapi memiliki fleksibilitas mulur (elongation) yang cukup besar.

TABEL 2. Data hasil pengujian kain loreng pixel design.

\begin{tabular}{|c|c|c|}
\hline JENIS UJI & HASIL UJI & STANDAR SNI/ISO \\
\hline Berat Kain $/ \mathrm{m}^{2}$ & 213.0 & $200-300$ \\
\hline \multicolumn{3}{|l|}{ Konstruksi Kain } \\
\hline Tetal lusi helai/cm (in) & $42.0 / 105.0$ & $35-45$ \\
\hline Tetal Pakan helai/cm (in) & $20.0 / 50.0$ & $15-20$ \\
\hline Nomor benang lusi $\mathrm{Ne}_{1}$ (Tex) & $20.0(29.4)$ & $15-20$ \\
\hline Nomor benang pakan $\mathrm{Ne}_{1}(\mathrm{Tex})$ & $15.0(40.0)$ & $15-20$ \\
\hline Anyaman & Keper $2 / 1 / 1$ & Keper/Rib \\
\hline \multicolumn{3}{|l|}{ Kekuatan Tarik dan Mulur } \\
\hline Kekuatan Tarik arah lusi N (kg) & $630.0(64.0)$ & $500-600$ \\
\hline Mulur (\%) & 11.0 & $10-15$ \\
\hline Kekuatan Tarik arah pakan N (kg) & $345.0(35.0)$ & $300-350$ \\
\hline Mulur (\%) & 12.0 & $10-15$ \\
\hline \multicolumn{3}{|l|}{ Kekuatan Sobek Kain } \\
\hline Arah lusi N (g) & $38.0(4.0)$ & $35-55$ \\
\hline Arah pakan N (g) & $34.0(3.5)$ & $25-35$ \\
\hline \multicolumn{3}{|l|}{ Komposisi (\%) } \\
\hline Kapas & 70.0 & $65-70$ \\
\hline Poliester & 30.0 & $35-30$ \\
\hline \multicolumn{3}{|l|}{ Ketahanan Luntur Warna. } \\
\hline a. Pencucian (GS/SS pe \&k) & $(4-5 / 4-5 / 4-5)$ & $(4-5)$ \\
\hline b. Gosokan (kering/ basah) & $(4 / 3)$ & $(4 / 3)$ \\
\hline \multicolumn{3}{|l|}{ c. Keringat: } \\
\hline Asam (GS/SS pe \& k) & $(4-5 / 4-5 / 4-5)$ & $(4-5)$ \\
\hline Basa & $(4-5 / 4-5 / 4-5)$ & $(4-5)$ \\
\hline d. Sinar Terang Hari (BW S) & $4-5$ & $4-5$ \\
\hline \multicolumn{3}{|l|}{ Identifikasi zat warna pada serat } \\
\hline Kapas & Bejana/Vat & Vat/Bejana \\
\hline Poliester & Disperse & Disperse \\
\hline
\end{tabular}

Kekuatan tarik kain loreng pixel design arah lusi $(630.0 \mathrm{~N} / 65.0 \mathrm{~kg})$ lebih tinggi dari pada SNI-ISO (500-600 N) karena akan menghadapi banyak gaya tarikan atau tegangan pada waktu digunakan maka dibuat agar kekuatan tariknya lebih tinggi. Kekuatan tarik arah pakan $(345.0 \mathrm{~N} / 35.0 \mathrm{~kg}$ ) masuk ke dalam SNI-ISO. Sedangkan Mulur (elongation) ke arah lusinya $(11.0 \%)$ dan ke arah pakan $(12.0 \%)$. Kekuatan tarik yang dihasilkan dari konstruksi diatas membuktikan bahwa kekuatan kain ke arah vertikal dapat melampaui standar sesuai dengan tujuan yang diinginkan. Sedangkan kekuatan tarik kain ke horizontal cukup tinggi dan tetap masuk ke dalam SNI-ISO. Mulur (elongation) ke arah vertikal maupun horizontal relatip sama rendah. Hal ini menjadi ciri khas dari kain yang terbuat dari bahan alam kapas atau campuran dari bahan alam kapas dengan bahan sintetis dimana komposisi kapasnya lebih banyak. Kain dengan elongation yang besar seperti pada seragam olahraga yang fleksibel tidak cocok untuk kain tempur yang padat. Selain itu, teknik pembuatannya juga berbeda.

Hasil uji kekuatan sobek arah lusi kain loreng pixel design $38.0 \mathrm{~N} / 4.0 \mathrm{~g}$, sedangkan arah pakannya $34.0 \mathrm{~N} / 3.5 \mathrm{~g}$ masih sesuai SNI-ISO. Kekuatan sobek kain baik ke arah vertikal maupun horizontal didisain untuk cukup memenuhi SNI-ISO karena dalam banyak kasus menunjukkan bahwa sobeknya kain yang disebabkan tersangkut kawat berduri atau ranting yang tajam pada saat operasi tidak signifikan.

Hasil uji komposisi loreng pixel design (C/P 70.0/30.0 \%) masih masuk kedalam SNI/ISO. Hal itu telah sesuai dengan rencana, maksud dan tujuan pembuatan kain loreng yang kuat berdasarkan terutama pada konstruksi, kekuatan tarik dan lain lainnya sehingga memenuhi SNI/ISO. Kadar kapas sebanyak 70\% merupakan inti kekuatan dari loreng pixel design sedangkan kandungan kapas hanya 30\% tidak akan mengurangi kekuatan dari bahan kapas bahkan meningkatkan sifat pixel design menjadi wash and wear atau no ironing. Dua komponen pada pixel design dapat saling mengisi kekurangan dan kelebihan sehingga menjadi kain yang kuat. 
Untuk pengujian ketahanan zat pewarna dilakukan terhadap ketahanan luntur kain terhadap pencucian dan keringat loreng pixel design menunjukkan nilai yang sama (4-5) pada gray scale dan staining scale. Adapun nilai dari skala ini tersebar dari 1-5. Angka 1 menunjukkan nilai yang terburuk dan angka 5 menunjukkan nilai yang terbaik. Hasil pengujian ketahanan terhadap gosokan menunjukkan nilai 4 (keadaan kering) dan 3 (keadaan basah) pada Staining Scale serta hasil uji ketahanan sinar terang hari menunjukkan nilai 4-5 pada blue wool scale. Semua jenis uji ketahanan kimia masih sesuai dengan SNI-ISO. Kain loreng pixel design hanya terdiri dari dua warna yaitu motif pixel berwarna coklat dan dasarnya warna khaki. Prinsip dari metoda pengujiannya adalah equivalen dari pemakaian 75 kali pakai-cuci-jemur-setrika dan dipakai kembali. Jadi dengan jumlah pemakaian yang banyak itu, loreng pixel design ditargetkan masih mempunyai kecerahan warna yang baik. Untuk dapat memenuhi tuntutan tersebut maka kuncinya adalah pada pemilihan zat pewarna yang terbaik kualitasnya. Zat pewarna yang baik akan membentuk ikatan kimia yang kuat secara molekuler dengan bahan tekstil sehingga menjadi bagian yang tidak terpisahkan dengan cara apapun. Hal inilah yang membedakan secara kimia antara loreng pixel design dengan bahan bukan loreng.

Hasil pengujian golongan zat warna pada loreng pixel design menunjukkan adanya zat warna dispersi (Disperse dyes) di dalam serat polyester dan zat warna bejana (vat dyes) pada serat kapas. Hal itu karena keduanya adalah kombinasi pasangan zat warna yang kualitasnya sangat baik dan sesuai dengan yang disarankan oleh SNI-ISO. Vat dyes bersifat hidrofilik sedangkan pasangannya disperse dyes bersifat hidrofobik. Disisi lain, Kain pixel design dengan komposisi 70/30\% C/P juga bersifat hidrofilik dan hidrofobik. Maka dari kesamaan sifat tersebut, vat dyes akan berikatan dengan Kapas dan disperse dyes akan berikatan dengan polyester sehingga menghasilkan kain pixel design yang memiliki daya tahan luntur yang tinggi.

\section{KESIMPULAN}

Kain loreng pixel design yang diuji kualitasnya berdasarkan persyaratan standar khusus militer dan tetap mengacu kepada SNI-ISO menghasilkan data hasil pengujian dari beberapa jenis uji seperti Berat Kain $/ \mathrm{m}^{2}$, ketahanan luntur warna, kekuatan sobek (lusi), kekuatan sobek (lusi), mulur (lusi dan pakan) dan identifikasi zat pewarna menunjukkan angka yang moderat atau berada didalam ambang batas SNI-ISO. Data hasil pengujian menunjukkan angka yang mendekati batas atas maksimum dari SNI-ISO yaitu konstruksi kain kecuali nomor benang pakan, kekuatan tarik (pakan), kekuatan sobek (pakan), komposisi dan ketahanan luntur warna. Dari data hasil pengujian menunjukkan angka ekstrim yang lebih tinggi dari SNI-ISO yaitu kekuatan tarik (lusi/vertikal). Hal itu disebabkan karena kain loreng ini terdiri dari benang lusi yang halus, baik dan tetal yang tinggi serta komposisi yang maksimum dari kedua bahan bakunya. Secara umum kain loreng pixel design memenuhi syarat SNI-ISO.

\section{DAFTAR PUSTAKA}

[1] Budiman A. Setyawan, Pengembangan Disain Kain Loreng Militer Motif Hutan Semak, Prosiding, Sentra UMM, Malang, Desember 2018.

[2] Budiman Adi setyawan, Analisa Kekuatan dan Ketahanan Luntur Kain Loreng Singlecam Berbasis Standar Nasional Indonesia, Jurnal Bina Teknika , FTUPNVJ, Jakarta, Mei 2014

[3] Budiman Adi Setyawan, Analisa Kekuatan dan Ketahanan Luntur Kain Loreng "Indian army" berbasis Standar Nasional Indonesia, Jurnal Bina Teknika, FTUPNVJ, Jakarta, Mei 2015

[4] Budiman A. Setyawan, Studi Komparasi Kualitas Kain Loreng NATO terhadap Loreng TNI berbasis Standar Nasional Indonesia, Prosiding, Sentra UMM, Malang, Nopember 2019. 
[5] https: //id.wikipedia.org/wiki/piksel

[6] BBIT, Serat-serat Tekstil, BBIT, Bandung, 2010

[7] BBIT, Kimia Zat Warna, BBIT, Bandung, 2010

[8] BBIT, Standar kain seragam TNI, Standar-Standar Kain Khusus, BBIT Bandung., 2010.

[9] BBIT, Evalusi Tekstil, BBIT, Bandung, 2010.

[10] Budiman A. Setyawan, Perancangan Awal Pengembangan Disain Kain Loreng Loreng Militer Motif Hutan Semak, Jurnal Konversi Energi dan Manufaktur, UNJ, Edisi II-Oktober 2018. 